\title{
Iodine Deficiency Disorder and Knowledge about Benefit and Food Source of Iodine among Adolescent Girls in the North Shewa Zone of Amhara Region
}

\author{
Abayneh Birlie Zeru, ${ }^{1}$ Mikyas Arega Muluneh, ${ }^{2}$ Kassa Ketsela H Giorgis, ${ }^{3}$ \\ Mulat Mossie Menalu $\left(\mathbb{D},{ }^{3}\right.$ and Michael Amera Tizazu $\mathbb{D D}^{2}$ \\ ${ }^{1}$ Department of Public Health, Institute of Medicine and Health Science, Debre Berhan University, Debre Berhan, Ethiopia \\ ${ }^{2}$ Department of Midwifery, Institute of Medicine and Health Science, Debre Berhan University, Debre Berhan, Ethiopia \\ ${ }^{3}$ Department of Nursing, Institute of Medicine and Health Science, Debre Berhan University, Debre Berhan, Ethiopia
}

Correspondence should be addressed to Michael Amera Tizazu; michaelamera12@gmail.com

Received 19 September 2020; Revised 30 December 2020; Accepted 7 January 2021; Published 13 January 2021

Academic Editor: Karen L. Sweazea

Copyright (c) 2021 Abayneh Birlie Zeru et al. This is an open access article distributed under the Creative Commons Attribution License, which permits unrestricted use, distribution, and reproduction in any medium, provided the original work is properly cited.

\begin{abstract}
Background. As the dietary iodine content depends on the iodine contents of the soil where the crop is harvested, in highland areas where the iodine content of topsoil was washed away due to erosion, iodized salt is the main source of iodine. This study assessed the magnitude of iodine deficiency disorder and knowledge about the benefit and food sources of iodine among adolescent girls in the highland areas of the North Shewa Zone, Amhara Region, central Ethiopia. Methods. An institutional cross-sectional study was conducted from October 5, 2018, to December 30, 2019. Through a multistage sampling technique, 625 adolescent school girls were selected from 9 schools. A pretested semistructured self-administered questionnaire was used for data collection. Anthropometric measures and thyroid gland physical examinations were performed by trained nurses. The collected data were entered into the computer through Epi Data 3.1 software, and analysis was performed using Anthro plus and SPSS software. Results. The total goiter rate was 317 (50.7\%) with 95\%CI of $46.9 \%$ to 54.6\%. Grade-one and grade-two goiter accounts 226 (36.2\%) and 91 (14.6\%), respectively. About one-third, 428 (68.5\%), had knowledge about locally available iodine source foods and 309 (72.2\%) of them mentioned salt as a source of iodine. Over half, 216 (55.1\%), of 392 (62.7\%) participants who had knowledge about the benefit of iodine knew it prevents goiter. Diet diversity score of $<5$ food groups [AOR 1.487, 95\%CI 1.061-2.083], stunting [AOR 1.876, 95\%CI 1.079-3.257], menstruation [AOR 1.615, 95\%CI 1.110-2.349], rural residence [AOR 1.412, 95\%CI 1.005-1.984], and open salt storage container [AOR 2.001, 95\%CI 1.044-3.833] were significantly associated with goiter. Conclusions. Total goiter rate of adolescent school girls is high in the area. Low diet diversity score, stunting, menstruation, rural residence, and using an open container for salt storage increased the risk of goiter. In addition to universal salt iodization, the emphasis has to be given on proper handling and utilization of iodized salts at the household level to avoid iodine deficiency disorder in adolescent girls.
\end{abstract}

\section{Introduction}

Adolescence, which is from age 10 to 19 years, is a period of rapid growth of skeletal mass, body size, and body density which highlights the role of nutrients and minerals in the growth process. Due to gender inequality and other physiological needs, adolescent girls are more vulnerable for malnutrition including micronutrient deficiency $[1,2]$.
Iodine deficiency (ID) is one of those common micronutrient deficiencies during adolescence which results in enlargement of the thyroid gland known as goiter, mental retardation, and physical growth retardation. These clinical and subclinical abnormalities related to ID are termed as iodine deficiency disorder (IDD) [2-6]. But, in adolescent girls, the effect of ID could extend to the fetus and newborns during their motherhood. Mild to moderate ID during 
pregnancy impairs fetal brain development and reduces child communication skill and, later, school performance and IQ. In addition, it increases the risk of stillbirth, abortions, perinatal deaths, infant mortality, and congenital anomalies [6-8].

To prevent this intergenerational effect of ID, securing adequate iodine intake for adolescent girls before pregnancy is an optimal strategy. Recognizing the importance of preventing IDD, the World Health Organization (WHO) recommended universal salt iodization as the main strategy to achieve the elimination of IDD $[9,10]$. Ethiopia started enforcing the comprehensive salt regulation which mandates universal salt iodization in 2012 GC. Since then, iodized salt coverage showed improvement; however, adequately iodized salt coverage is still low $[11,12]$.

Most IDD-related local studies focused on school-age (6-12 years) children, and those few studies conducted on adolescent girls revealed that goiter is a common public health problem in Ethiopia. The goiter rate among adolescents in Ethiopia varies from place to place ranging from $25.1 \%$ to $48.9 \%$ [13-15]. Adolescent girls are over two-folds more at risk of goiter than adolescent boys [16]. Grade-one goiter is more prevalent in girls aged 10-14 years, and grade II goiter is more common in 15-19-year-old girls [17].

Because of topsoil erosion where iodine is usually found, there is low dietary iodine content in crops cultivated in Ethiopian highland areas. This means iodized salt is the main dietary source of iodine in those areas $[13,18]$. Therefore, it is important to assess the magnitude of IDD and knowledge about the benefits and food sources of iodine among adolescent girls in the highland area of the North Shewa Zone, central Ethiopia.

\section{Methods and Materials}

2.1. Study Design and Setting. An institution-based crosssectional study was conducted from October 5, 2018, to December 30, 2019. Adolescent girls who attend public schools in the North Shewa Zone of Amhara Region, central Ethiopia, were taken as the study population. The North Shewa Zone is one of the eleven zones found in the Amhara regional state. The North Shewa Zone is located at a latitude $9^{\circ} 46^{\prime} 8.4^{\prime \prime} \mathrm{N}$ and longitude $39^{\circ} 40^{\prime} 4.8^{\prime \prime} \mathrm{E}$ with an average elevation of 2840 meters above sea level. For administrative purposes, the North Shewa Zone had been divided into 24 districts and 4 town administration units.

2.2. Sample Size and Sampling Procedure. The sample size was determined using Epi Info version 7.1.5.0 software by considering $29.3 \%$ prevalence of goiter [13], 5\% marginal error, 95\% confidence level, and a design effect of 2 . We got a total sample size of 636 .

A multistage sampling technique was employed to get study participants. First, 3 districts (Debre-Sina, Basona werena, and Deneda) from 14 highland districts in the zone were selected using the lottery method. Second, from each selected district, 2 primary schools, rural and urban primary schools, were selected by the lottery method. Since all high schools are located in urban areas, we randomly selected one high school from the selected districts. Three rural primary schools, 3 urban primary schools, and 3 urban high schools, which give a total of 9 schools, were identified for the study. Third, lists of adolescent girls aged from 10-19 years were obtained from each selected school; then, through simple random sampling, the study participants were proportionally recruited from each school for the study.

2.3. Data Collection Tools and Procedures. Data were collected by trained female nurses through face-to-face interviews using a semistructured questionnaire and physical examination. The interview was conducted at school during class free time, and it took, on average, 25-30 minutes. The questionnaire was developed by reviewing different kinds of literature and contextually adapted to sociocultural norms and agroclimatic conditions of the study area. The questionnaire was divided into four parts: sociodemographic, dietary practices, anthropometric measurements, and thyroid examination.

Diet diversity assessment: diet diversity was measured by adapting the Minimum Diet Diversity for Women (MDD-W) questionnaire by recalling foods and beverages consumed the previous day and night. The questionnaire was developed by the Food and Nutrition Technical Assistance (FANTA) project to reflect the micronutrient adequacy of women's diets. It has 22 mutually exclusive food groups and categories, of which 14 aggregated to create the MDD-W 10 food group indicator. The ten MDD-W food groups are grains, white roots and tubers, and plantains; pulses (beans, peas, and lentils); nuts and seeds; dairy; meat, poultry, and fish; eggs; dark green leafy vegetables; other vitamin A-rich fruits and vegetables; other vegetables; and other fruits. From those 10 food groups, a minimum of 5 food groups should be consumed in 24 hours to get adequate micronutrients for women. Therefore, a diet diversity score (DDS) of $\geq 5$ was considered adequate [19].

Anthropometric measurement: height was measured to the nearest $0.1 \mathrm{~cm}$ with barefoot, and weight was measured to the nearest $0.1 \mathrm{~kg}$ with light clothing. Body mass index (BMI) was obtained from WHO Anthro plus software which divides the weight (measured in $\mathrm{kg}$ ) to the square of the height (measured in meters) of study participants. Similarly, the height-for-age $Z$ score (HAZ) and BMI-for-age $Z$ score (BAZ) were computed using WHO Anthro plus software. Adolescent girls having an HAZ of $<-2$ were considered as stunted, and those with $<-3$ were severely considered stunted. Adolescent girls with a BAZ of $<-2$ were thin, and those with $<-3$ were taken as severely thin $[20,21]$.

Goiter assessment: the enlargement of the thyroid gland related to iodine deficiency was assessed through examination of the thyroid gland. Goiter status was used to assess the IDD of study participants. Those female nurses trained 
for the data collection also examined study participants for thyroid gland enlargement. Accordingly, the level of goiter was graded as follows:

Grade 0: if there is no palpable or visible goiter. Grade one: if the goiter is palpable but not visible. Grade two: if the goiter is visible and palpable under the normal position of the neck according to the WHO recommendation. The total goiter rate of adolescent girls was measured by considering both grade-one and -two goiters. A separate classroom was used for goiter assessment to make girls feel free to show their necks for examination $[3,22]$.

2.4. Data Quality Assurance. The English version of the questionnaire was translated into the local language (Amharic), and the consistency was checked by retranslating back to English and compared with the original version. The Amharic version of the questionnaire was pretested on 25 adolescent school girls to check its understandability by the study participant, response rate to each question, and determine the time required per questionnaire. One-day training on the objective of the study, on data collection tool, and procedure including how to examine the thyroid gland was given for three female data collectors and one supervisor. Daily monitoring and supervision of the data collection and checking for completeness and consistency of collected data were carried out by the supervisor. The principal investigator also examined the collected data for completeness and consistency before data entry.

2.5. Data Analysis Procedures. Data were entered into Epi Data 3.1 software and then exported to WHO Anthro plus version 3.1.0 and SPSS version 24 software for analysis. HAZ and BAZ were computed using the WHO Anthro plus software. Descriptive statistics was made to see the sociodemographic characteristics and goiter rate of adolescent school girls. Both bivariable and multivariable binary logistic regression analyses were used to identify factors associated with goiter. Variables with a $p$ value of less than 0.25 on the bivariable analysis and nutritionally relevant were considered as candidate variables for further multivariable analysis. Odds ratios (OR) with $95 \%$ confidence intervals (95\%CI) were computed, and variables with a $p$ value $<0.05$ on multivariable analysis were considered as statistically significant risk factors for goiter.

\section{Results}

3.1. Sociodemographic Characteristics. From the total 636 sampled study participants for the study, 625 were involved in the data collection, making a response rate of $98.3 \%$. The mean $( \pm \mathrm{SD})$ age of study participants was $15.0( \pm 2.1)$ years. Two hundred and thirty-three (37.3\%) and 156 (25.0\%) were in the age categories of 10-14 and 17-19 years, respectively. Over half, 328 (52.5\%) and 339 (54.2\%), of the participants were primary school attendants and rural residents, respectively. The majority, 224 (37.5\%), of mothers of the study participants cannot write and read. The majority of, 363 (59.2\%), mothers and, 435 (74.1\%), fathers of study participants were housewives and farmers, respectively (Table 1).

3.2. Goiter Rate, Nutritional Status, and Dietary Practices. The overall prevalence of goiter was 317 (50.7\%) with 95\% CI of $46.9 \%$ to $54.6 \%$. Of those, $226(36.2 \%)$ were grade-one and $91(14.6 \%)$ grade-two goiter. Seven $(1.1 \%)$ and 65 (10.4\%) participants had severe and moderate stunting, respectively. The overall prevalence of stunting was $72(11.5 \%)$ with $95 \%$ CI of $9.1 \%$ to $14.2 \%$. From 53 (8.5\%) with $95 \%$ CI of $6.3 \%$ to $10.6 \%$ study participants with thinness, $5(0.8 \%)$ had severe thinness and $48(7.7 \%)$ had moderate thinness (Table 2).

Thirty-seven (5.9\%) participants had a meal frequency of less than three per day. The mean $( \pm S D)$ DDS of study participants was $5.01 \pm 1.85$. Two hundred and eighty-three (45.3\%) had consumed less than the minimum required number of food groups ( $<5$ good items) in the last 24 hours (Table 2).

From those 10 food items, grains, 564 (90.2\%), were the most frequently consumed food item followed by other vegetables, 508 (81.3\%), and pulses, 435 (69.6\%). The chisquare test showed that dark green-leafy vegetable consumption showed a significant association with goiter of adolescent school girls ( $p$ value $<0.001$ ). Grains, white roots and tubers, pulses, other fruits, and other vegetables also were associated with goiter. DDS was significantly associated to goiter $(p$ value $=0.005)($ Table 3$)$.

3.3. Knowledge of the Benefit of Iodine and Iodine Food Sources. Four hundred and twenty-eight (68.5\%) study participants believed they knew locally available iodine source foods and the majority, 309 (72.2\%), of them mentioned salt as a source of iodine. From 392 (62.7\%) participants who knew the benefit of iodine, prevention of goiter, $216(55.1 \%)$, and good health, $178(45.4 \%)$, were more frequently mentioned. From 376 (60.2\%) participants who had awareness of salt iodization, 148 (39.4\%) mentioned their teachers as a primary source of information. Though most, 568 (90.9\%), households of the study participants used closed containers for salt storage, $432(69.1 \%)$ had habits of adding salt at the beginning or middle of the food cooking process (Table 4).

3.4. Factors Associated with Goiter. Variables (age, residence, menstrual onset, DDS, type of salt used at the household, and stunting) which had a $p$ value $<0.25$ on bivariable analysis and nutritionally relevant variables such as wasting, meal frequency, and usual salt adding time in the cooking process were included in the multivariable analysis (Table 5).

On the final model, DDS, stunting, menstrual onset, and residence had a statistically significant association with goiter. As compared to those who had $\geq 5$ DDS, the risk of goiter was 1.49 times higher among adolescent school girls who had <5 DDS [AOR; 1.487 and 95\%CI; 1.061-2.083]. Stunted adolescent school girls had $87.6 \%$ higher odds of 
TABLE 1: Sociodemographic characteristics of participants in the North Shewa Zone, 2019.

\begin{tabular}{|c|c|c|}
\hline Variables & Responses & Frequency(\%) \\
\hline \multirow{3}{*}{ Age (in years) } & $10-14$ & $233(37.3)$ \\
\hline & $15-16$ & $236(37.8)$ \\
\hline & $17-19$ & $156(25.0)$ \\
\hline \multirow{2}{*}{ School } & Primary school & $328(52.5)$ \\
\hline & High school & $297(47.5)$ \\
\hline \multirow{3}{*}{ Residence } & Rural & $339(54.2)$ \\
\hline & Urban & $286(45.8)$ \\
\hline & Christian & $603(96.4)$ \\
\hline \multirow[t]{2}{*}{ Religion } & Muslim & $16(2.6)$ \\
\hline & Others & $6(1.0)$ \\
\hline \multirow{2}{*}{ Ethnicity } & Amhara & $616(98.6)$ \\
\hline & Others & $9(1.4)$ \\
\hline \multirow{5}{*}{$\begin{array}{l}\text { Mother educational } \\
\text { status }\end{array}$} & Cannot read and write & $224(37.5)$ \\
\hline & Can read and write & $219(36.7)$ \\
\hline & Up to grade 8 & $105(17.6)$ \\
\hline & Grade 9 to 12 & $24(4.0)$ \\
\hline & $\begin{array}{l}\text { College certificate and } \\
\text { above }\end{array}$ & $25(4.2)$ \\
\hline \multirow{5}{*}{$\begin{array}{l}\text { Father's educational } \\
\text { status }\end{array}$} & Cannot read and write & $85(14.7)$ \\
\hline & Can read and write & $300(51.7)$ \\
\hline & Up to grade 8 & $108(18.6)$ \\
\hline & Grade 9 to 12 & $48(8.3)$ \\
\hline & $\begin{array}{l}\text { College certificate and } \\
\text { above }\end{array}$ & $39(6.7)$ \\
\hline \multirow{6}{*}{ Mother's occupation } & House wife & $363(59.2)$ \\
\hline & Farmer & $123(20.1)$ \\
\hline & Merchant & $56(9.1)$ \\
\hline & Government employee & $31(5.1)$ \\
\hline & Private employee & $27(4.4)$ \\
\hline & Others & $13(2.1)$ \\
\hline \multirow{5}{*}{ Father's occupation } & Farmer & $435(74.1)$ \\
\hline & Merchant & $49(8.3)$ \\
\hline & Government employee & $63(10.7)$ \\
\hline & Private employee & $27(4.6)$ \\
\hline & Others & $13(2.2)$ \\
\hline \multirow{2}{*}{ Family size } & $<5$ & $206(33.0)$ \\
\hline & $\geq 5$ & $419(67.0)$ \\
\hline
\end{tabular}

having goiter than their counterparts [AOR; 1.876; 95\%CI; 1.079-3.257]. The odds of goiter were $61.5 \%$ higher among menstruating adolescent school girls compared to their counterparts [AOR; 1.615 and 95\%CI; 1.110-2.349]. Rural residents had over $41 \%$ higher odds of developing goiter than urban adolescent school girls [AOR; 1.412 and 95\%CI; $1.005-1.984]$. Using open salt storage containers at household increased the odds of goiter by two-folds [AOR; 2.001 and 95\%CI; 1.044-3.833] (Table 5).

\section{Discussion}

In this study, based on the size of thyroid gland enlargement, $36.2 \%$ and $14.6 \%$ of adolescent school girls had grade-one and grade-two goiter, respectively. The overall goiter rate was $50.7 \%$ which reflected that, over half of adolescent school girls were suffering from IDD in the North Shewa
TABLE 2: Prevalence of goiter, malnutrition, and dietary practices of study participants, 2019.

\begin{tabular}{lcc}
\hline Variables & Responses & Frequency (\%) \\
\hline \multirow{4}{*}{ Goiter } & Grade 0 & $308(49.3)$ \\
& Grade I & $226(36.2)$ \\
Grade II & $91(14.6)$ \\
HAZ & Severe stunting $(<-3 S D)$ & $7(1.1)$ \\
& Mild stunting $(<-2 S D)$ & $65(10.4)$ \\
BAZ & Normal $(\geq-2 S D)$ & $553(88.5)$ \\
& Severe thinness $(<-3 S D)$ & $5(0.8)$ \\
DDS & Mild thinness $(<-2 S D)$ & $48(7.7)$ \\
& Normal $(\geq-2 S D)$ & $572(91.5)$ \\
Meal frequency & $<5$ food groups & $283(45.3)$ \\
& $\geq 5$ food groups & $342(54.7)$ \\
& $\leq 2$ meals per day & $37(5.9)$ \\
& 3 meals per day & $306(49.0)$ \\
\hline
\end{tabular}

Abbreviations: $\mathrm{HAZ}$, height-for-age $Z$ score; $\mathrm{BAZ}$, BMI-for-age $Z$ score; DDS, diet diversity score.

Zone highland districts. This is consistent with a $48.9 \%$ total goiter rate $(36.9 \%$ grade I and $11.11 .9 \%$ grade II) report in Southern Ethiopia [14]. However, it was higher than the report of $39.5 \%$ goiter rate among 6-18-year-old girls in Metekel, Northwest Ethiopia [15]. Likewise, it is higher than the $31 \%$ total goiter rate among mothers in the highland of the Amhara Region, Ethiopia [13]. This goiter prevalence is much higher than the cutoff point of $\geq 5 \%$ population goiter rate recommendation of the WHO $[22,23]$ to define IDD as an endemic public health problem. This higher goiter rate in the North Shewa Zone may be related to improper holding and utilization of iodized salt at the household level. Perhaps, it could be due to low dietary iodine intake which is related to the low iodine content of common crops harvested and eaten in the area. The highland areas of the North Shewa Zone are more mountainous and vulnerable for iodinecontaining topsoil erosion. As a result, common foods crops harvested and consumed by the community in the area may lack adequate iodine content.

In this study, $68.5 \%$ of adolescent girls knew locally available iodine-rich foods which are similar to the $70 \%$ report in Northwest Ethiopia [24] and higher than the 61.9\% report in Wellega Province of Ethiopia [25]. This study revealed that $62.7 \%$ of adolescent girls knew the benefits of iodine and $55.1 \%$ of them recognized that it is important to prevent goiter. This finding goes in line with the 2015 national report that two-thirds of women in Ethiopia had awareness about goiter and $48 \%$ of them were able to associate goiter with iodine deficiency [26].

MDD-W is one of the best indicators of micronutrient intake adequacy. The current study revealed that the odds of goiter were 1.49 times higher among adolescent school girls who consumed less than 5 food groups than their counterparts, which is in line with the finding of a study in the Dabat district of northwest Ethiopia [27]. This is because when the DDS is high, girls will get adequate nutrients such as iodine for the increased demand during the puberty 
TABLE 3: Diet diversity and its relationship with goiter among study participants, 2019.

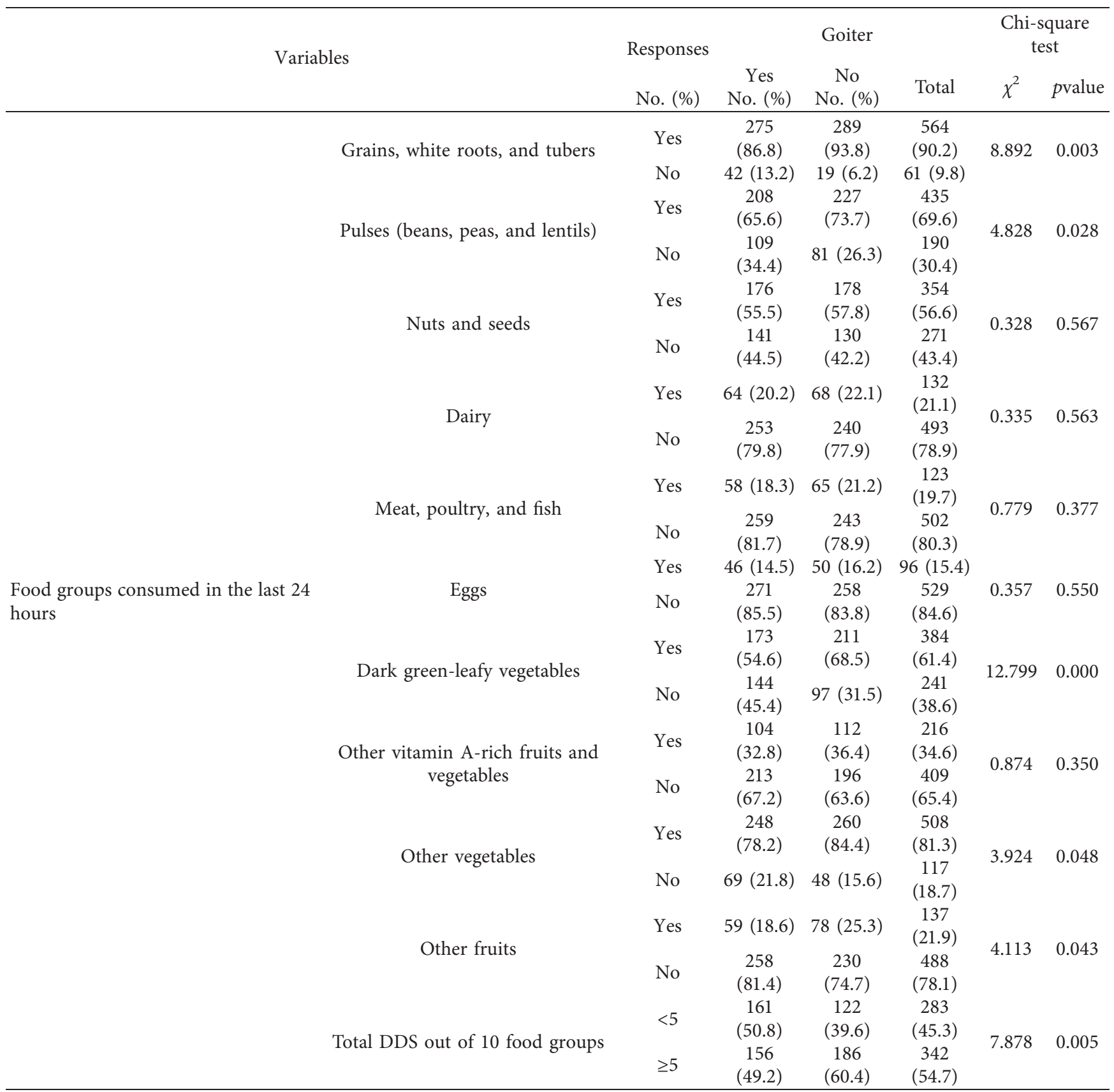

Abbreviation: DDS, diet diversity score.

period. For a population with grains/cereal-based dietary habits, low DDS could lead to iodine deficiency and related disorder of goiter.

Despite the evidence that most packed salts are adequately iodized $(\geq 15 \mathrm{ppm})$ than unpacked salts and salt iodization is the most effective interventional strategy to prevent IDDs such as goiter [28-30], in this study, the type of salt utilized by the household was not significantly associated with goiter. This could be because of the incorrect timing of salt adding in the food cooking process as over two-thirds, 432 (69.1\%), households of adolescent girls in this study usually add salts at the beginning or in the middle of the cooking process. The appropriate time of adding iodized salt to food during cooking is at the end or immediately before the end of cooking to avoid iodine loss through evaporation which reflects the importance of proper handling utilization of iodized salts beside the universal salt iodization to prevent IDD. The level of iodine loss during cooking depends upon the type of cooking procedures and time of addition of salt $[31,32]$. Though there is universal salt iodization, because of improper utilization of iodized salts, foods are the main source of iodine in this study area.

This study revealed that postmenarche adolescent girls were $61.5 \%$ more at risk of goiter than premenarche girls. 
TABLE 4: Knowledge about the benefits and food sources of iodine by study participants, 2019 .

\begin{tabular}{|c|c|c|}
\hline Variables & Responses & Frequency (\%) \\
\hline \multirow{2}{*}{ Do you know locally available foods used as a source of iodine? $(n=625)$} & Yes & $428(68.5)$ \\
\hline & No & $197(31.5)$ \\
\hline \multirow{6}{*}{ Iodine source foods $(n=428)$} & Salt & $309(72.2)$ \\
\hline & Cereals & $81(18.9)$ \\
\hline & Legumes & $69(16.1)$ \\
\hline & Fruits & $29(6)$. \\
\hline & Vegetables & $57(13.3)$ \\
\hline & Others & $15(3.5)$ \\
\hline \multirow{2}{*}{ Do you know the benefit of iodine-rich foods? $(n=625)$} & Yes & $392(62.7)$ \\
\hline & No & $233(37.3)$ \\
\hline \multirow{7}{*}{ Benefits of iodine $(n=392)$} & Prevents goiter & $216(55.1)$ \\
\hline & Good health & $178(45.4)$ \\
\hline & Prevent cretinism & $84(21.4)$ \\
\hline & Mental development & $80(20.4)$ \\
\hline & Physical growth & $73(18.6)$ \\
\hline & Prevent abortion or still birth & $32(8.2)$ \\
\hline & Others & $21(5.3)$ \\
\hline \multirow{2}{*}{ Heard about iodized salt $(n=625)$} & Yes & $376(60.2)$ \\
\hline & No & $249(39.8)$ \\
\hline \multirow{5}{*}{ Primary source of information $(n=376)$} & Teachers & $148(39.4)$ \\
\hline & Mass media & $136(36.2)$ \\
\hline & Health workers & $106(28.2)$ \\
\hline & Relatives/friends & $46(12.2)$ \\
\hline & Others & $22(5.1)$ \\
\hline \multirow{3}{*}{ Type of salt used $(n=625)$} & Packed & $375(60.0)$ \\
\hline & Unpacked & $205(32.8)$ \\
\hline & Both & $45(7.2)$ \\
\hline \multirow{2}{*}{ Salt storage container $(n=625)$} & Closed container & $568(90.9)$ \\
\hline & Open container & $57(9.1)$ \\
\hline \multirow{4}{*}{ Usual time of adding salt during cooking $(n=625)$} & At the beginning of cooking & $122(19.5)$ \\
\hline & In the middle of cooking & $310(49.6)$ \\
\hline & Immediately before the end of cooking & $153(24.5)$ \\
\hline & After cooking & $40(6.4)$ \\
\hline
\end{tabular}

TABLE 5: Bivariate and multivariate analysis of factors associated with goiter among adolescent girls, 2019.

\begin{tabular}{|c|c|c|c|c|c|c|c|}
\hline \multirow{2}{*}{ Variables } & \multirow{2}{*}{ Responses } & \multicolumn{2}{|c|}{ Goiter } & \multicolumn{2}{|c|}{ Bivariable analysis } & \multicolumn{2}{|c|}{ Multivariable analysis } \\
\hline & & Yes & No & COR $(95 \% \mathrm{CI})$ & $p$ value & AOR $(95 \% \mathrm{CI})$ & $p$ value \\
\hline \multirow{3}{*}{ Age } & $10-14$ & 109 & 124 & 1 & & 1 & \\
\hline & $15-16$ & 120 & 116 & $\begin{array}{c}1.771 \\
(0.819-1.691)\end{array}$ & 0.378 & $0.828(0.509-1.348)$ & 0.498 \\
\hline & $17-19$ & 88 & 68 & $\begin{array}{c}1.472 \\
(0.979-2.214)\end{array}$ & 0.063 & $0.881(0.501-1.551)$ & 0.938 \\
\hline \multirow[t]{2}{*}{ Residence } & Rural & 180 & 159 & $\begin{array}{c}1.231 \\
(0.898-1.687)\end{array}$ & 0.196 & $1.412(1.005-1.984)^{*}$ & 0.049 \\
\hline & Urban & 137 & 149 & 1 & & 1 & \\
\hline \multirow[t]{2}{*}{ Menstrual onset } & Yes & 229 & 189 & $\begin{array}{c}1.639 \\
(1.171-2.293)\end{array}$ & 0.04 & $1.615(1.110-2.349)^{*}$ & 0.031 \\
\hline & No & 88 & 119 & 1 & & 1 & \\
\hline \multirow[t]{2}{*}{ DDS } & $<5$ food groups & 161 & 122 & $\begin{array}{c}1.573 \\
(1.146-2.161)\end{array}$ & 0.005 & $1.487(1.061-2.083)^{*}$ & 0.018 \\
\hline & $\geq 5$ food groups & 156 & 186 & 1 & & 1 & \\
\hline \multirow{3}{*}{ Meal frequency } & $\leq$ twice times day & 21 & 16 & $\begin{array}{c}1.276 \\
(0.639-2.546)\end{array}$ & 0.489 & $1.181(0.569-2.452)$ & 0.614 \\
\hline & Three times day & 153 & 153 & $\begin{array}{c}0.972 \\
(0.703-1.343)\end{array}$ & 0.864 & $0.809(0.573-1.142)$ & 0.280 \\
\hline & $\geq$ four times day & 143 & 139 & 1 & & 1 & \\
\hline
\end{tabular}


TABLE 5: Continued.

\begin{tabular}{|c|c|c|c|c|c|c|c|}
\hline \multirow{2}{*}{ Variables } & \multirow{2}{*}{ Responses } & \multicolumn{2}{|c|}{ Goiter } & \multicolumn{2}{|c|}{ Bivariable analysis } & \multicolumn{2}{|c|}{ Multivariable analysis } \\
\hline & & Yes & No & COR $(95 \% \mathrm{CI})$ & $p$ value & AOR $(95 \% \mathrm{CI})$ & $p$ value \\
\hline \multirow[t]{2}{*}{ Stunted } & Yes & 45 & 27 & $\begin{array}{c}1.722 \\
(1.039-2.854)\end{array}$ & 0.034 & $\begin{array}{c}1.876 \\
(1.079-3.257)^{*}\end{array}$ & 0.044 \\
\hline & No & 272 & 281 & 1 & & 1 & \\
\hline \multirow[t]{3}{*}{ Wasted } & Yes & 28 & 25 & $\begin{array}{c}1.097 \\
(0.624-1.927)\end{array}$ & 0.748 & $1.359(0.720-2.563)$ & 0.416 \\
\hline & No & 289 & 283 & 1 & & 1 & \\
\hline & Packed & 179 & 196 & 1 & & 1 & \\
\hline \multirow{3}{*}{$\begin{array}{l}\text { Type of salt used at the } \\
\text { household }\end{array}$} & Unpacked & 115 & 90 & $\begin{array}{c}1.399 \\
(0.994-1.970)\end{array}$ & 0.054 & $1.232(0.831-1.825)$ & 0.081 \\
\hline & Both & 23 & 22 & $\begin{array}{c}1.145 \\
(0.617-2.125)\end{array}$ & 0.668 & $0.844(0.392-1.814)$ & 0.421 \\
\hline & Closed & 280 & 288 & 1 & & 1 & \\
\hline Type of salt storage container & Open & 37 & 20 & $\begin{array}{c}1.903 \\
(1.078-3.359)\end{array}$ & 0.025 & $2.001(1.044-3.833)^{*}$ & 0.037 \\
\hline \multirow{4}{*}{ Usual salt adding time } & Before cooking starts & 60 & 62 & 1 & & 1 & \\
\hline & In the middle of cooking & 161 & 149 & $\begin{array}{c}1.117 \\
(0.734-1.699)\end{array}$ & 0.606 & $1.238(0.766-2.001)$ & 0.678 \\
\hline & $\begin{array}{l}\text { Immediately before the end of } \\
\text { cooking }\end{array}$ & 77 & 76 & $\begin{array}{c}1.047 \\
(0.651-1.685)\end{array}$ & 0.850 & $1.383(0.795-2.405)$ & 0.607 \\
\hline & After cooking & 19 & 21 & $\begin{array}{c}0.935 \\
(0.457-1.911)\end{array}$ & 0.573 & $0.862(0.387-1.911)$ & 0.714 \\
\hline
\end{tabular}

Note: * significantly associated variables at a $p$ value $<0.05$. DDS, diet diversity score; COR, crude odds ratio; AOR, adjusted odds ratio.

According to a study in Switzerland [33] during the mid to late puberty, period girls are more susceptible to goiter even with mild iodine deficiency. This coincidence between goiter and menarche may be related to the sex steroid hormones which promote modulation of the hypothalamic-pituitarythyroid gland axis. The positive influence of estrogens and minor inhibitory effect of androgens on the circulating thyroid hormone affects thyroid function [34]. This could increase the physiological demand for iodine nutrients during puberty, exacerbate the existing iodine deficiency, and probably lead to the enlargement of thyroid glands in those girls with mild iodine deficiency.

Nutritional status is another risk factor independently associated with goiter. Both goiter and stunting are indicators of long-standing nutritional problems; in this study, stunted adolescent school girls were more likely to have goiter than their counterparts. Likewise, studies in Nigeria showed that stunting is related to goiter [35] and low urine iodine levels [36].

Similar to the finding of a study in the Sawla district of Southern Ethiopia [37], the residence was found to be a risk factor for goiter in the current study. As compared to urban residents, goiter was $41.2 \%$ more likely to be observed in rural resident adolescent school girls. The association between goiter and rural residency may be because of a lack of awareness about the cause and preventive methods of goiter which may include improper storage and utilization of iodized salts at the household level.

Despite the large sample size of adolescent girls involved in the study as a strength, this study must have the following limitations: the recent iodine level of study participants was not measured using urinary iodine concentration or iodine content of salt used at the household level; rather, we used total goiter rate which is a less sensitive indicator of IDD. Since the goiter status of study participants was measured through observation and physical examination, there may be nondifferential misclassifications during grading the level of goiter by the data collectors. As a cross-sectional study, the observed association between those identified risk factors and goiter should be interpreted with caution.

\section{Conclusions}

There was a high $(50.7 \%)$ total goiter rate among adolescent school girls in the North Shewa Zone highland area. Adolescent school girls with low DDS, stunting, menstruation, and rural residency were more likely to have goiter. In addition to universal salt iodization, the emphasis has to be given on proper handling and utilization of iodized salts at the household level to avoid IDD on adolescent girls. The knowledge of adolescent girls about the benefits of iodine-rich foods was low (62.7\%), and only half (55.1\%) of them had an awareness that iodine-rich foods are important for the prevention of goiter.

\section{List of Abbreviations}

BAZ: $\quad$ BMI-for-age $Z$ score

HAZ: $\quad$ Height-for-age $Z$ score

IDD: Iodine deficiency disorder

DDS: Diet diversity score

MDD-W: Minimum siet diversity for women 


\section{Data Availability}

The datasets used and/or analyzed during the current study are available from the corresponding author on reasonable request.

\section{Ethical Approval}

A letter of ethical clearance was obtained from the Ethical Review Committee of Debre Berhan University. A permission letter was also obtained from the zonal health office, woreda health office, and each selected school.

\section{Consent}

We obtained written consent from study participants aged 15 years, and for those less than 15 years of age, verbal consent from teachers and assent from participants was obtained. For confidentiality purposes, the names of the participants were not included in the questionnaire.

\section{Conflicts of Interest}

The authors declare that they have no conflicts of interest.

\section{Authors' Contributions}

$\mathrm{AB}$ designed the investigation, carried out the data analyses, interpreted the results, and drafted the manuscript; MA facilitated the data collection, interpreted the results, and reviewed and revised the manuscript. All authors read and approved the final manuscript.

\section{Acknowledgments}

The authors acknowledge the district education offices and school directors for their consent and assistance. The authors are sincerely grateful to the study participants and data collectors for their full involvement in the data collection process. The authors thank Debre Berhan University for material and financial support.

\section{References}

[1] World Health Organization, Nutrition in Adolescence: Issues and Challenges for the Health Sector: Issues in Adolescent Health and Development, WHO, Geneva, Switzerland, 2005.

[2] Food and Agriculture Organization, "Human vitamin and mineral requirements: report of a joint $\mathrm{FAO} / \mathrm{WHO}$ expert consultation bangkok, Thailand," Food and Agriculture Organization, Rome, Italy, 2001.

[3] T. G. Amabye, "Knowledge of iodine deficiency disorders and intake of iodized salt in residents of mekelle tigray, Ethiopia," International Journal of Food Sciences and Nutrition, vol. 4, no. 4, pp. 208-214, 2015.

[4] T. Belachew, A. Gebremariam, W. Legesse et al., Micronutrient Deficiency: For the Ethiopian Health Center Team, Jimma University, Jimma, Ethiopia, 2005.

[5] T. Khara, E. Mates, and F. Mason, Adolescent Nutrition: Policy and Programming in SUN+ Countries, Save the Children, London, UK, 2015.
[6] Nutrition and Physical Activity Guidelines for Adolescents, Adolescent Nutrition, UCSF, University of California, San Francisco, CA, USA, 2013.

[7] M. Markhus, L. Dahl, V. Moe et al., "Maternal iodine status is associated with offspring language skills in infancy and toddlerhood," Nutrients, vol. 10, no. 9, p. 1270, 2018.

[8] D. Levie, T. I. M. Korevaar, S. C. Bath et al., "Association of maternal iodine status with child IQ: a meta-analysis of individual participant data," The Journal of Clinical Endocrinology \& Metabolism, vol. 104, no. 12, pp. 5957-5967, 2019.

[9] UNICEF-WHO Joint Committee on Health Policy, World Summit for Children - Mid Decade Goal: Iodine Deficiency Disorders, United Nations Children's Fund, World Health Organization, Geneva, Switzerland, JCHPSS/94/2.7), 1994.

[10] WHO, UNICEF. World Health Organization, United Nations Children's Fund, Joint Statement: Reaching Optimal Iodine Nutrition in Pregnant and Lactating Women and Young Children, World Health Organization, Geneva, Switzerland, 2007.

[11] 2017 Remarkable progress against iodine deficiency in Ethiopia. Idd Newsletter.

[12] T. Chuko, J. Bagriansky, and A. T. Brown, Ethiopia's long road to USI. Idd Newsletter, 2015.

[13] C. Abuye, Y. Berhane, and T Ersumo, "The role of changing diet and altitude on goitre prevalence in five regional states in Ethiopia," East African Journal of Public Health, vol. 5, no. 3, pp. 163-168, 2008.

[14] S. B. Workie, Y. G. Abebe, A. A. Gelaye, and T. C. Mekonen, "Assessing the status of iodine deficiency disorder (IDD) and associated factors in Wolaita and Dawro Zones School Adolescents, southern Ethiopia," BMC Research Notes, vol. 10, p. 156, 2017.

[15] G. Kibatu, E. Nibret, and M. Gedefaw, "The status of iodine nutrition and iodine deficiency disorders among school children in Metekel zone, Northwest Ethiopia," Ethiopian Journal of Health Sciences, vol. 23, no. 1, pp. 109-116, 2014.

[16] Y. Mezgebu, A. Mossie, P. Rajesh, and G. Beyene, "Prevalence and severity of iodine deficiency disorder among children 612 years of age in Shebe Senbo district, Jimma zone, Southwest Ethiopia," Ethiopian Journal of Health Sciences, vol. 22, no. 3, pp. 196-204, 2012.

[17] R. Mushtaq, M. Ramzan, and A. Bibi, "Effects of iodine defiency goiter on academic performance of girls," Biomedica, vol. 30, no. 1, pp. 40-43, 2014.

[18] M. Zimmermann, Key Barriers to Global Iodine Deficiency Disorder Control: A Summery, Human Nutrition Laboratory, Swiss Federal Institute of technology Zürich (Ethz), Zürich, Switzerland, 2007.

[19] FaF, Minimum Dietary Diversity for Women: A Guide for Measurement, FAO, Rome, 2016.

[20] A. R. Masterson, P. Murakwani, and Z. Mlobane, Assessment of Adolescent Girl Nutrition, Dietary Practices, and Roles in zimbabwe, International Medical Corps, Zimbabwe, Africa, 2015.

[21] A. Sinha, H. Sharma, P. Panda, A. Chandrakar, S. Pradhan, and S. Dixit, "Prevalence of goitre, iodine uptake and salt iodization level in Mahasamund district of Chhattisgarh: a baseline study in Central India," International Journal of Research in Medical Sciences, vol. 4, no. 8, pp. 3590-3594, 2016.

[22] World Health Organization, Assessment of Iodine Deficiency Disorders and Monitoring Their Elimination: A Guide for Programme Managers, World Health Organization, Geneva, Switzerland, 3 edition, 2007. 
[23] World Health Organization, Iodine Status Worldwide: WHO Global Database on Iodine Defifciency, Bd Benoist, M. Andersson, I. Egli, B. Takkouche, and H. Allen, Eds., World Health Organization, Geneva, Switzerland, 2004.

[24] T. Demissie, "Availability and knowledge of iodized salt at household level and associated factors at Debre tabor town, northwest Ethiopia," Journal of Nutrition and Health Sciences, vol. 6, no. 1, p. 101, 2019.

[25] Z. F. Abessa and Y. J. Mashalla, "Knowledge about goitre among female school-going children in Wellega Province, Ethiopia," Tanzania Journal of Health Research, vol. 20, no. 4, 2018.

[26] A. Hailu, Ethiopian National Micronutrient Survey Report, Ethiopian Public Health Institute Ministry of Health, Addis Ababa, Ethiopia, 2016.

[27] Z. Abebe, E. Gebeye, and A. Tariku, "Poor dietary diversity, wealth status and use of un-iodized salt are associated with goiter among school children: a cross-sectional study in Ethiopia," BMC Public Health, vol. 17, p. 44, 2017.

[28] World Health Organization, Goitre as a Determinant of the Prevalence and Severity of Iodine Deficiency Disorders in Populations, Vitamin and Mineral Nutrition Information System, World Health Organization, Geneva, Switzerland, 2014, http://apps.who.int/iris/bitstream/10665/133706/1/ WHO_NMH_NHD_EPG_14.5_eng.pdf?ua $=1$.

[29] N. Aburto, M. Abudou, V. Candeias, and T. Wu, Effect and safety of salt iodization to prevent iodine deficiency disorders: a systematic review with meta-analyses, WHO eLibrary of Evidence for Nutrition Actions (eLENA), World Health Organization, Geneva, Switzerland, 2014.

[30] UNICEF, Guidance On the Monitoring of Salt Iodization Programmes and Determination of Population Iodine Status, UNICEF, NY, New York, 2015.

[31] R. Rana and R. S. Raghuvanshi, "Effect of different cooking methods on iodine losses," Journal of Food Science and Technology, vol. 50, no. 6, pp. 1212-1216, 2013.

[32] K. M. Y. K. Sikdar, A. Ganguly, A. S. M. M.-A.- Hossain, and A. B. M. Faroque, "Estimation of loss of iodine from edible iodized salt during cooking of various bangladeshi food preparations," Dhaka University Journal of Pharmaceutical Sciences, vol. 15, no. 2, pp. 161-165, 2016.

[33] Y. Fleury, G. Van Melle, V. Woringer, R. C. Gaillard, and L. Portmann, "Sex-dependent variations and timing of thyroid growth during Pubertyl," The Journal of Clinical Endocrinology \& Metabolism, vol. 86, no. 2, pp. 750-754, 2001.

[34] L. Dalla Valle, A. Ramina, S. Vianello, A. Fassina, P. Belvedere, and L. Colombo, "Potential for estrogen synthesis and action in human normal and neoplastic thyroid Tissues1," The Journal of Clinical Endocrinology \& Metabolism, vol. 83, no. 10, pp. 3702-3709, 1998.

[35] R. A. Sanusi and N. N. Ekerette, "Nutrition and goiter status of primary school children in ibadan, Nigeria," African Journal of Biomedical Research, vol. 12, no. 1, pp. 37-41, 2009.

[36] N. J. Ugo and O. E. Chinwe, "A pilot study of iodine and anthropometric status of primary school children in Obukpa, a rural Nigerian community," Journal of Public Health and Epidemiology, vol. 4, no. 9, pp. 246-252, 2012.

[37] D. L. kebede and Y. M. Adinew, "Predictors of goiter among school children in Southwest Ethiopia: case control study," Journal of Nutrition \& Food Sciences, vol. 5, no. 3, p. 368, 2015. 